\title{
Financial Literacy and Financial Planning in France
}

\author{
Luc Arrondel \\ CNRS-PSE and Banque de France, luc.arrondel@ens.fr \\ Majdi Debbich \\ Banque de France and PSE, majdi.debbich@banque-france.fr \\ Frédérique Savignac \\ Banque de France, frederique.savignac@banque-france.fr
}

Follow this and additional works at: https://digitalcommons.usf.edu/numeracy

Part of the Behavioral Economics Commons, Econometrics Commons, and the Finance Commons

\section{Recommended Citation}

Arrondel, Luc, Majdi Debbich, and Frédérique Savignac. "Financial Literacy and Financial Planning in France." Numeracy 6, Iss. 2 (2013): Article 8. DOI: http://dx.doi.org/10.5038/1936-4660.6.2.8 


\title{
Financial Literacy and Financial Planning in France
}

\begin{abstract}
We study financial literacy in France using the PATER survey and following the Lusardi and Mitchell (2011c) approach. We find that some subpopulations are less financially literate than others: women, young and old people as well as less-educated people are more likely to face difficulties when dealing with fundamental financial concepts such as risk diversification and inflation and interest compounding. We also find some differences in financial knowledge depending on the political opinion of the respondents. Finally we show that these differences in financial knowledge are correlated with differences in the propensity to plan: people who score higher on the financial literacy questions are more likely to be engaged in the preparation of a clearly defined financial plan.
\end{abstract}

\section{Keywords}

financial literacy, retirement planning, household finance

\section{Creative Commons License}

\section{c) (i) (8)}

This work is licensed under a Creative Commons Attribution-Noncommercial 4.0 License

\section{Cover Page Footnote}

Luc Arrondel is Research Director at the Centre National de Recherche Scientifique, the primary research organization in France, and he is assigned at the Paris School of Economics. He is also Scientific Advisor at Banque de France. As an economist specializing in applied microeconometrics, his research focuses primarily on the theoretical and empirical aspects of individual saving behavior. His work combines participation in the elaboration of household surveys administered by various national organizations (INSEE) and the construction of purpose-specific surveys designed to elicit the attitudes of the french population vis-a-vis wealth accumulation (with TNS-Sofres).

Majdi Debbich is a PhD candidate at the Paris School of Economics and teaching assistant at University Panthéon-Sorbonne, Paris, France. He also works as a junior economist in the Division of Microeconomic Analysis at Banque de France. He holds an M.Sc. in Economics from the Paris School of Economics and a bachelor's degree from University Panthéon-Sorbonne.

Frédérique Savignac is a senior researcher at Banque de France where she is also Deputy Head of the Division of Microeconomic Analysis. She completed her PhD at University Panthéon-Sorbonne, Paris, France, in 2006. From 2003 to 2005 she was a junior economist in the Companies Directorate at Banque de France before spending one year at the National Institute of Statistics and Economic Studies (INSEE), Malakoff, France. 


\section{Introduction}

Since World War II, the welfare state has played a central role in France's retirement pension system. But structural population aging combined with sluggish economic growth have put a strain on the French "pay-as-you-go" pension system. By 2050, the number of retired households is expected to increase by $60 \%$ while the working population will increase by not more than 10\% (Observatoire des retraites 2009). Moreover, in 2011 the retirement deficit reached 14 billion euros (COR 2013) though major reforms were carried out in the last decade. ${ }^{1}$ French households have generally high savings rates despite the importance of public pensions. ${ }^{2}$ Major concerns are thus mainly about households' portfolio choices and wealth accumulation rather than their ability to save.

From a policy perspective, identifying key determinants of financial planning is crucial to designing efficient policies that encourage households' finances to be "long-term oriented." Indeed, Ameriks et al. (2003) show that the propensity to plan plays a significant role in explaining differences in wealth accumulation. In particular, Lusardi and Mitchell (2011b) show that American adults who can correctly answer financial literacy questions are much more likely to plan for retirement. However, as cultural and institutional environments are obviously different across developed countries (and in particular between the United States and France, for instance as regards pension systems), assessing the level of financial literacy as well as its impact on household finances, portfolio choices, or retirement planning remains an open research question.

This paper contributes to this literature. First, we assess the extent to which French households are financially sophisticated enough to deal with fundamental financial concepts. Second, we investigate the link between financial literacy and the propensity to plan for retirement in France.

Our empirical analysis is based on data from the PATER (PATrimoines et Préférences face au TEmps et au Risque) household survey, an original survey that mainly aims to measure households' saving preferences. The 2011 wave surveys a representative sample of French adults and includes questions to assess respondents' understanding of basic financial concepts (interest, inflation, and

\footnotetext{
${ }^{1}$ In 2003, the reform known as loi Fillon lengthened the contribution period and implemented mechanisms to foster the employment of seniors. This reform also started a shift from an unfunded to a funded pension system. Along the same lines, a new 2010 reform has strengthened these provisions. See Ben Salem et al. (2010) for a more complete picture of pension reforms in France.
}

2 The gross household saving rate ranged between $13.4 \%$ and $16.3 \%$ in the years $2000-2012$. 
risk), following the methodology proposed by Lusardi and Mitchell (2011c), in addition to questions on financial planning (as suggested in Ameriks et al. 2003).

Based on this survey, we assess levels of financial literacy in France. The results we obtain suggest that financial literacy should not be taken for granted, as most respondents do not exhibit mastery of the fundamentals of economics and finance. This finding is in line with results from other developed countries (Lusardi and Mitchell 2011a). Some French subpopulations display low levels of financial literacy: women, young people, and the elderly as well as less-educated people. We also find that financial literacy is correlated with political affiliation, which could reflect differences in opinion regarding the role of the welfare state and individual responsibility. Finally, we find a significant positive relationship between the propensity to formulate a specific financial plan in the long run (which entails retirement planning) and financial literacy.

This paper is organized as follows. The first section provides a brief overview of the data set and descriptive statistics, with subsections addressing the following three questions: (i) How financially literate are individuals in France? (ii) Who knows the least? and (iii) Does financial literacy vary across political opinions? The second section investigates the relationship between retirement planning and financial literacy. The final section concludes.

\section{Data and Descriptive Statistics}

\section{The PATER Survey}

The PATER household survey was first conducted by the French National Statistics Institute (Institut national de la statistique et des études économiques, or INSEE) in 1998 and then repeated four times until 2011 upon our own initiative in cooperation with Taylor-Nelson Sofres (TNS Sofres), a private survey company (Arrondel and Masson 2013). This survey focuses on preferences (risk aversion, time preference, and altruism), but it also covers a wide range of topics regarding households' saving behavior, financial literacy, expectations, and political opinions in addition to wealth, income, socioeconomic, and demographic characteristics for a representative sample of French households.

The module on financial literacy was introduced in the 2011 wave. The paper-based questionnaire was sent out in November 2011 to a representative sample of 5,000 individuals. Respondents in this wave were sampled from the TNS Sofres metascope panel (30,000 households): two-thirds of the sample had been surveyed in the 2009 wave.

Respondents had to fill in the questionnaire and return it by mail in exchange for a twenty euro shopping voucher. A total of 3,616 households sent back their questionnaire, representing a 72.3\% response rate. Any member of the household 
could answer the questionnaire but more than $70 \%$ of respondents claimed to be in charge of the family finances.

\section{How Financially Literate Are Individuals?}

To assess the level of financial literacy in the French population, the PATER survey included a module following the benchmark questions proposed by Lusardi and Mitchell (2011c) and additional questions on financial culture. We restrict our analysis to three questions to enable our results to be comparable with other countries' results: understanding of interest compounding and understanding of inflation (both to assess basic numeracy) and understanding of risk diversification (which is more specifically related to portfolio choices). The wording of the question on inflation in the PATER survey corresponds exactly to the benchmark proposed by Lusardi and Mitchell (2011c). Regarding the question on interest compounding, ours is slightly harder to answer as it requires that the respondent grasp the difference between simple and compound interest. The other difference worth noting is on the risk diversification question. In the benchmark, respondents are simply asked to say whether a statement is true or false. In our questionnaire, we ask respondents to rank several financial products according to their level of risk. Using this information, we construct a variable that only considers the relative ranking of stocks versus shares of a mutual fund regardless of other assets' ranking. bold):

The exact wording of the questions is as follows (correct answers are in

1) Suppose you had $€ 1,000$ in a savings account and the interest rate was $2 \%$ per year. After 5 year, how much do you think you would have in the account if you let the money to grow?

Less than $€ 1,100$

Exactly $€ 1,100$

\section{More than $€ 1,100$}

Do not know

No answer

2) Imagine that the interest rate on your savings account was 1\% per year and inflation was $2 \%$ per year. After 1 year, how much would you be able to buy with the money in this account?

More than today

Same as today

Less than today

Do not know

No answer 
3) Rank these financial products from the less risky to the riskiest:

Saving account, Stock, Bond, Share of a mutual fund

Do not know/No answer

For the risk diversification question, we consider the answer to be correct when "stock" is ranked as being riskier than "share of a mutual fund" and incorrect otherwise. "Do not know" refers to respondents having checked a box stating they do not know the answer while "no answer" refers to respondents who have completely skipped the question. The distinction between "do not know" and "no answer" can be made in the first two questions but not in the third. Summary statistics are provided in Table 1 for the whole population and for the subsample of respondents age 25-65.

Table 1

Summary Statistics on Financial Literacy Questions (weighted \%)

\begin{tabular}{lcc} 
A: Interest Question & Full Sample & Age 25-65 \\
Less than $€ 1,100$ & 47.98 & 50.33 \\
Equal to $€ 1,100$ & 27.64 & 27.87 \\
Greater than $€ 1,100$ & 7.16 & 7.12 \\
DK & 11.53 & 10.30 \\
RF & 5.69 & 4.38 \\
B: Inflation Question & & \\
More & 2.68 & 2.66 \\
Exactly the same & 8.77 & 9.38 \\
Less & 61.18 & 61.69 \\
DK & 21.32 & 21.36 \\
RF & 6.06 & 4.91 \\
C: Risk Question* & & \\
Correct & 66.85 & 72.13 \\
Incorrect & 18.53 & 18.14 \\
DK/RF & 14.61 & 9.73 \\
D: Cross-question Consistency & & \\
Interest \& Inflation & 37.88 & 39.56 \\
All correct & 30.92 & 33.76 \\
None correct & 15.15 & 12.36 \\
At least 1 DK & 33.39 & 29.45 \\
All DK & 2.70 & 1.90 \\
\# Observations & $\mathbf{3 , 6 1 6}$ & $\mathbf{2 , 4 5 9}$ \\
\hline Source: PATER 2011. & & \\
Notes: $D K$ indicates respondent selected “do not know”; RF indicates respondent did not answer the \\
question. & & \\
* To construct this variable we consider only the relative ranking of stock versus share of a mutual \\
fund and define the answer to be correct when stock is ranked as being riskier than a share of a \\
mutual fund. & & \\
& &
\end{tabular}

Nearly $48 \%$ of respondents correctly answer the question on interest compounding (Panel A). This share rises to a bit more than half when we focus on respondents age 25 to 65 . As already mentioned, our question on interest compounding is harder than the benchmark question because it requires a broad understanding of interest computation and an understanding of the difference between simple and compound interest. However, the question wording in the French survey is the same as that in the Russian survey (Klapper and Panos 2011) 
and similar to the wording in the Swedish survey. ${ }^{3}$ These countries have, respectively, 36\% and 35\% of respondents answering correctly. Other countries (United States with 65\%, Germany with 82\%, Italy with $40 \%$, and the Netherlands with $85 \%{ }^{4}$ ) use the simpler benchmark interest question. ${ }^{5}$ Therefore, it is hard to disentangle whether differences in response rates are due to differences in financial literacy levels or to the wording of the question when making international comparisons. ${ }^{6}$ In any case, it is still striking to notice that even when a list of potential answers is provided, half of French respondents fail to give the correct answer to the interest question. Apart from difference in wording, framing effects are likely to influence the assessment of financial literacy (see, among others, Van Rooij et al. 2012). In our survey, an additional question was added to measure respondents' ability to compute compound interest in a nonfinancial context. This question refers to the well-known board game Monopoly. ${ }^{7}$ We find that less than $20 \%$ of the sample correctly answers the Monopoly question (see Appendix Table A1), while this share was $48 \%$ in a financial context. Although the Monopoly question requires a stronger computational effort and maybe a calculator close at hand, this difference still illustrates the sensitivity of financial literacy measures to framing and wording effects.

Regarding the concept of inflation (Panel B), 61\% of the full sample display an understanding of the impact of inflation on purchasing power while more than $10 \%$ give an incorrect answer, and a quarter does not know the answer. Figures for the subsample of respondents age 25 to 65 are roughly similar. These results are in line with those found in other countries with percentage of correct answers

\footnotetext{
${ }^{3}$ The question in the Swedish survey asks, "Suppose you have 200 SEK in a savings account. The interest is $10 \%$ per year and is paid into the same account. How much will you have in the account after two years?” Possible answers are respondent calculation, don't know, and refuse to answer (Almenberg and Säve-Söderbergh 2011).

${ }^{4}$ See Lusardi and Mitchell (2011b) for the United States, Bucher-Koenen and Lusardi (2011) for Germany, Fornero and Monticone (2011) for Italy, and Alessie et al. (2011) for the Netherlands.

${ }^{5}$ The benchmark wording is as follows for the US survey: "Suppose you had \$100 in a savings account and the interest rate was $2 \%$ per year. After 5 years, how much do you think you would have in the account if you left the money to grow? \$102; More/Less than \$102; Don’t know.”

${ }^{6}$ Two other French studies, more descriptive, can be compared with our results. Credoc (2011) uses the benchmark question on interest and gets a correct response rate of 54\%. Haas (2012) uses the same wording as ours and gets a correct response rate of $47 \%$.

${ }^{7}$ The wording of this question is as follows: "You play Monopoly. You have earned $€ 1000$ and the bank offers to pay $20 \%$ every time you go through the corner square GO. You need $€ 2000$ to buy a hotel. How often do you need to pass through the first corner square to buy the hotel? $1 ; 2$; 3; 4; 5; More than 5 times; Don't know.”
} 
ranging from 59.5\% in Sweden (Almenberg and Säve-Söderbergh 2011) to 78.4\% in Germany (Bucher-Koenen and Lusardi 2011).

Following the popular adage "don't put all your eggs in one basket," respondents appear to have less difficulty correctly answering the third question on risk diversification (Panel C). However, the wording and structure of this question differ enough from the benchmark to call for caution when making international comparisons. About two-thirds of our sample gets the question on risk diversification right, while around $15 \%$ do not know/do not answer. Percentage of correct answers is around $72 \%$ for respondents age 25 to 65 while the share offering no answer stands at around $10 \%$.

Each of these three questions contributes to measuring the multidimensional concept of financial literacy. It is therefore interesting to check the extent to which these variables are related. We find that less than $40 \%$ of respondents can correctly answer both the compound interest and the inflation questions, and less than a third (31\%) gets all three questions correct (Panel D). Another third of the sample fails to answer at least one question, and 15\% does not provide any correct answer to the three questions.

\section{Who Knows the Least?}

Financial literacy appears to be low at the aggregate level, but this hides large differences among population subgroups. When performing cross-tabulations by characteristics such as age, education, gender, and employment status, we find that some sociodemographic groups are particularly financially illiterate (see Table 2). Most of these differences continue to hold even after accounting for individual characteristics (see Appendix Table A3).

Broadly speaking, younger respondents and older respondents tend to answer less correctly than those in the middle of the age range This reflects the common hump-shaped pattern of financial literacy and cognitive abilities along the age spectrum that has been observed in other studies (see, among others, Van Rooij et al. 2011; Lusardi et al. 2012). While we cannot distinguish cohort from age effects with our cross-sectional data set, this pattern could result from the fact that in young adulthood, individuals begin accumulating financial knowledge and information (King and Leape 1987; Jappelli and Padula 2013; Lusardi et al. 2012), thus the percentage of correct answers increases with age. But with old age, cognitive capacity decreases and the benefits of life experience tend to be offset by declining cognition, causing the share of older respondents answering correctly to decrease (Agarwal et al. 2009). 
Table 2

Answers to Financial Literacy Questions by Sociodemographic Variables (weighted \%)

\begin{tabular}{lcccccccc}
\hline & \multicolumn{2}{c}{ Interest } & \multicolumn{2}{c}{ Inflation } & \multicolumn{3}{c}{ Risk } & \multicolumn{2}{c}{ Overall } \\
\cline { 2 - 9 } Age & Correct & DK & Correct & DK & Correct & DK/RF & 3 Correct & $>=1$ DK \\
Under 35 & 49.79 & 10.39 & 51.77 & 25.74 & 72.44 & 8.28 & 29.08 & 33.58 \\
36-50 & 52.08 & 10.22 & 62.69 & 21.70 & 74.81 & 8.09 & 35.57 & 28.22 \\
51-65 & 48.10 & 10.80 & 67.29 & 17.51 & 67.53 & 14.00 & 34.17 & 29.41 \\
Over 65 & 40.05 & 15.46 & 64.68 & 19.48 & 49.29 & 31.40 & 24.07 & 43.90 \\
Sex & & & & & & & & \\
Male & 52.39 & 8.94 & 67.14 & 16.66 & 70.37 & 13.04 & 36.29 & 28.12 \\
Female & 43.98 & 13.89 & 55.76 & 25.55 & 63.66 & 16.04 & 26.04 & 38.18 \\
Education & & & & & & & & \\
Primary (Isced 1) & 32.07 & 21.54 & 49.70 & 29.61 & 35.21 & 38.88 & 12.11 & 57.58 \\
Lower sec. (Isced 2) & 33.62 & 20.50 & 49.02 & 29.92 & 60.03 & 20.99 & 18.10 & 46.63 \\
Upper sec. (Isced 3) & 44.34 & 12.39 & 56.19 & 24.06 & 63.93 & 14.24 & 25.41 & 35.78 \\
Some college (Isced 5) & 55.62 & 7.73 & 70.13 & 16.56 & 79.10 & 9.06 & 41.44 & 25.10 \\
College grad (Isced 5) & 61.28 & 3.81 & 76.92 & 11.13 & 80.66 & 6.41 & 46.75 & 18.08 \\
Postgrad. (Isced 6) & 75.33 & 2.99 & 83.42 & 6.14 & 87.21 & 5.56 & 64.27 & 11.94 \\
Employment Status & & & & & & & & \\
Self-employed & 55.99 & 10.35 & 60.45 & 25.54 & 71.09 & 10.41 & 37.63 & 32.20 \\
Not employed & 43.34 & 16.29 & 53.70 & 28.62 & 66.06 & 13.58 & 25.32 & 40.15 \\
Working & 52.93 & 9.14 & 60.84 & 21.14 & 74.58 & 7.81 & 35.28 & 27.75 \\
Retired & 42.13 & 13.45 & 67.39 & 17.53 & 54.41 & 26.09 & 26.45 & 38.39 \\
\hline Source PATER 2015
\end{tabular}

Source: PATER 2011.

Notes: $D K$ indicates respondent selected "do not know"; $R F$ indicates respondent did not answer the question. $N=3,616$.

Regarding the interest compounding question, fewer than half of younger respondents answer correctly, and just 40\% of respondents older than 65 answer correctly. For the risk diversification question, it is striking that for most age groups, around $70 \%$ of respondents answer correctly, yet the proportion of older respondents answering correctly hardly reaches 50\%. As highlighted in Lusardi and Mitchell (2011a), the understanding of inflation is strongly influenced by experience. In France, the most recent inflationary period occurred in the early 1980s. It is therefore not surprising to observe that among the three questions, respondents above age 65 only outperform those under age 35 on the question about inflation, with $65 \%$ of this age group answering correctly. These figures confirm other papers' findings regarding low financial literacy among young respondents (Lusardi et al. 2010) and elderly respondents (Lusardi and Mitchell 2007; Lusardi and Tufano 2009a, 2009b).

Figures in Table 2 also suggest a heterogeneous pattern of answers across gender. First, men tend to be more likely to correctly answer each question. Indeed, $36 \%$ of men (compared to $26 \%$ of women) answer all of the questions correctly. Second, women tend to state they do not know the answer more often than men. This pattern is common and may reflect the fact that men exhibit overconfident behaviors while women are less prone to answer when they are unsure of the answer (Barber and Odean 2001). The highest difference between men and women is observed for the inflation question; a much higher proportion of men (67\%) than women (56\%) answer this question correctly. 
Educational attainment is also positively correlated with financial literacy. While hardly a third of respondents with a primary level of schooling succeed in correctly answering the question on interest compounding, this share rises to $75 \%$ for respondents with a postgraduate level of education. The same pattern is observed for the two other questions, and the gap is even wider when we consider the question on risk diversification for which the percentage of respondents answering correctly goes from $35 \%$ for primary level to $87 \%$ for postgraduate attainment. Along with this, the percentage of respondents reporting they do not know the answer decreases with the level of education. Responses to the inflation question show that answering correctly is again positively related to education. Respondents with a primary level of education tend to perform better on the inflation question (about 50\% answer correctly) than on the interest compounding (32\%) and risk diversification (35\%) questions, which could reflect the contribution of experience to correctly answering this question.

Scores also differ by employment status. Respondents who were not employed at the time of the survey perform much worse than do those who were employed or self-employed. The population that is not employed is also more prone than other respondents to reply "do not know." The highest percentages of correct answers to the inflation question are found in the retired population, as these respondents might have lived through periods of inflation. But this pattern does not persist when we control for other determinants such as education (see Appendix Table A3). All in all, middle-aged working men with higher levels of education tend to exhibit the highest level of financial literacy.

\section{Financial Literacy across Political Opinions}

In addition to the sociodemographic factors discussed above, ideological and cultural factors such as political opinions could explain differences across respondents in the propensity to correctly answer the financial literacy questions. Ideological opinion and political affiliation may play a part in financial behaviors such as stock holding or financial planning as well as in the importance people attach to financial knowledge (Bucher-Koenen and Lusardi 2011; Kaustia and Torstila 2011). In particular in France, Nadeau et al. (2010) demonstrate the relationship between wealth and political affiliation. Regarding financial literacy, left-wing voters are likely to be less "materialistic" and to believe that the welfare state should handle personal issues such as retirement pensions or healthcare insurance. These individuals might therefore be less sensitive to the importance of financial knowledge and might have invested less time in acquiring it. On the other hand, right-wing or center voters may consider it a personal responsibility to manage one's financial well-being; ${ }^{8}$ they could also be less in favor of a strong

\footnotetext{
8 In France, the centrist party has a rather "liberal" view of the economy.
} 
welfare state and more likely to devote time to being or becoming financially literate. Following this assumption, we should observe a higher level of financial literacy among right-wing or center voters than among left-wing voters. ${ }^{9}$

Table 3

Answers to Financial Literacy Questions by Political Opinion (weighted \%)

\begin{tabular}{|c|c|c|c|c|c|c|c|c|}
\hline \multirow[b]{2}{*}{ Political Opinion } & \multicolumn{2}{|c|}{ Interest } & \multicolumn{2}{|c|}{ Inflation } & \multicolumn{2}{|c|}{ Risk } & \multicolumn{2}{|c|}{ Overall } \\
\hline & Correct & DK & Correct & DK & Correct & DK/RF & 3 Correct & $>=1 \mathrm{DK}$ \\
\hline Left wing & 51.68 & 10.35 & 63.45 & 21.04 & 68.65 & 13.39 & 33.67 & 32.48 \\
\hline Center & 58.76 & 3.77 & 79.62 & 9.38 & 77.02 & 8.53 & 43.63 & 17.02 \\
\hline Right wing & 50.64 & 10.86 & 66.55 & 16.91 & 69.22 & 13.28 & 34.40 & 28.86 \\
\hline Anarchist & 50.45 & 19.47 & 62.13 & 25.46 & 65.07 & 19.76 & 32.94 & 34.93 \\
\hline $\begin{array}{l}\text { No political } \\
\text { opinion }\end{array}$ & 38.76 & 17.70 & 46.52 & 33.18 & 60.44 & 16.46 & 19.76 & 45.04 \\
\hline
\end{tabular}

Table 3 provides some evidence to partially confirm this hypothesis. ${ }^{10}$ On the one hand, people voting in the center perform better than others on every question, with percentages of correct answers ranging from 59\% for interest compounding to $80 \%$ for inflation. This result partly reflects the sociodemographic composition of centrist voters, who are more educated than those affiliating with other political parties (see Appendix Table A2). On the other hand, percentages of respondents correctly answering each question do not substantially differ between respondents with left-wing and right-wing affiliations: around $50 \%$ for interest compounding, $65 \%$ for inflation, and $69 \%$ for risk diversification for both affiliations.

Overall, one in three respondents provides a correct answer to all the questions regardless of political affiliation. The most notable difference is between respondents with no political opinion and other respondents. Respondents with no political opinion (in which women are overrepresented) tend to have much more difficulty answering correctly: $39 \%$ are correct on the interest compounding question, $47 \%$ on the inflation question, and $60 \%$ on the risk diversification question. One surprising result is the fact that right-wing voters are not more financially sophisticated than left-wing voters are. This might be due to the composition of the right-wing electorate gathering both "liberal" and "conservative voters" (Rémond 1969). Composition effects may be at work in the differences observed regarding financial literacy levels, but as shown in Appendix Table A3, differences remain statistically significant when we control for sociodemographic characteristics: centrist voters perform much better than others,

\footnotetext{
${ }^{9}$ For a more extensive description of the French political spectrum, see Elgie (2003).

${ }^{10}$ In the PATER survey, political opinion is elicited using the following question: "How do you position yourself in the political spectrum? Extreme left wing; Left wing; Centre left wing; Centre; Centre right wing; Right wing; Extreme right wing; Anarchist; No political opinion.”
} 
while respondents indicating they have no political affiliation lag far behind on the financial literacy measures.

\section{Financial Literacy and "Propensity to Plan for the Long Run"}

In this section, we study the link between financial literacy and individuals' propensity to plan and to make long-term financial decisions. We aim to investigate whether there is a positive relationship between financial literacy and retirement planning among the French, as is the case in the United States (Lusardi and Mitchell 2011b, 2011c).

The PATER survey contains a question designed to measure the propensity to plan, as suggested in Ameriks et al. (2003). Households were asked a yes/no question concerning their preparation of a specific long-term financial plan: ${ }^{11}$

Have you personally gathered together your household's financial information, reviewed it in detail, and formulated a specific financial plan for your household's long-term future?

This question appears suitable to assess retirement planning, as retirement planning is part of broader long-term financial planning. For the empirical analysis, we restrict the sample to nonretired respondents age 25 to 65. Among these respondents, about $25 \%$ are defined as "planners"; that is, they have answered "yes" to the above question. ${ }^{12}$ Cross-tabulations indicate that being a planner is correlated with correctly answering the financial literacy questions (see Table 4).

In addition to financial literacy, the propensity to plan for the long run may be related to individuals' preferences, permanent income, and lifetime horizon. In our empirical model, we consider variables that account for these factors: age (and age squared), gender, marital status, income levels, educational attainment, and employment status.

Three alternative measures for financial literacy are considered: a dummy variable $^{13}$ equal to one when respondents answer all three questions correctly; the

\footnotetext{
${ }^{11}$ Those with a positive answer were also asked to specify the age at which this activity was first undertaken.

12 Ameriks et al. (2003) estimate the percentage of planners to be 73\% in the United States. This high percentage may be due to the use of TIAA-CREF data, which comes from surveys of people owning retirement funds.

${ }^{13}$ In empirical economics, binary (or indicator or categorical) variables are typically referred to as dummy variables. These variables takes the value of zero or one to indicate the absence or presence of some categorical effect.
} 
sum of each respondent's number of correct answers to the financial literacy questions; a vector of three dummy variables indicating, for each question, whether the respondent answered correctly.

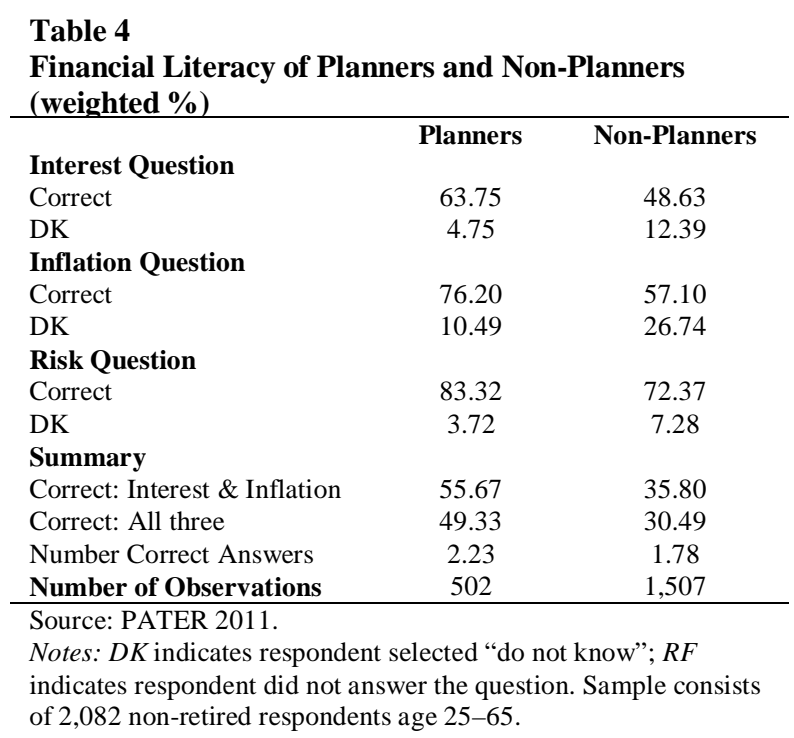

In all three cases, financial literacy appears to be positively and highly significantly correlated with the propensity to plan. Considering column 1 of Table 5, we see that correctly answering all three financial literacy questions increases the probability of planning by 9 percentage points. The average marginal impact of answering one extra question is a 5.5 percentage point increase in the probability to plan. Answering each question correctly has nearly the same impact on the probability to plan, though the impact is higher and more significant for the inflation question.

Other important determinants of financial planning are education and income. College graduates and higher-income earners have significantly higher probabilities of formulating a financial plan for the long term than do other respondents. The same pattern is observed in Italy (Fornero and Monticone 2011) and in the United States (Lusardi and Mitchell 2011b) concerning retirement planning, while other determinants — such as marital status or occupation-appear also to be at work. These estimates may suffer from several limitations. First, financial literacy may be measured with error. Second, there may be a problem of reverse causality: respondents who are already planners may increase their financial knowledge through experience. We have addressed the issue of endogeneity by using instrumental variables (IV) estimation and using 
instruments related to parents' financial knowledge and behavior. ${ }^{14}$ The endogeneity tests revealed that the financial literacy variable could actually be treated as exogenous. ${ }^{15}$ This could be explained by the fact that our measures of financial literacy refer to basic financial knowledge and are related to cognitive abilities. In this context, it is unlikely that reverse causality could bias our results, as financial planning can hardly enhance cognitive capacities. On the contrary, other financial literacy variables related to financial culture and information are more likely to be affected by endogeneity, as discussed in Arrondel et al. (2013).

Table 5

OLS Estimates of Financial Planning on Financial Literacy

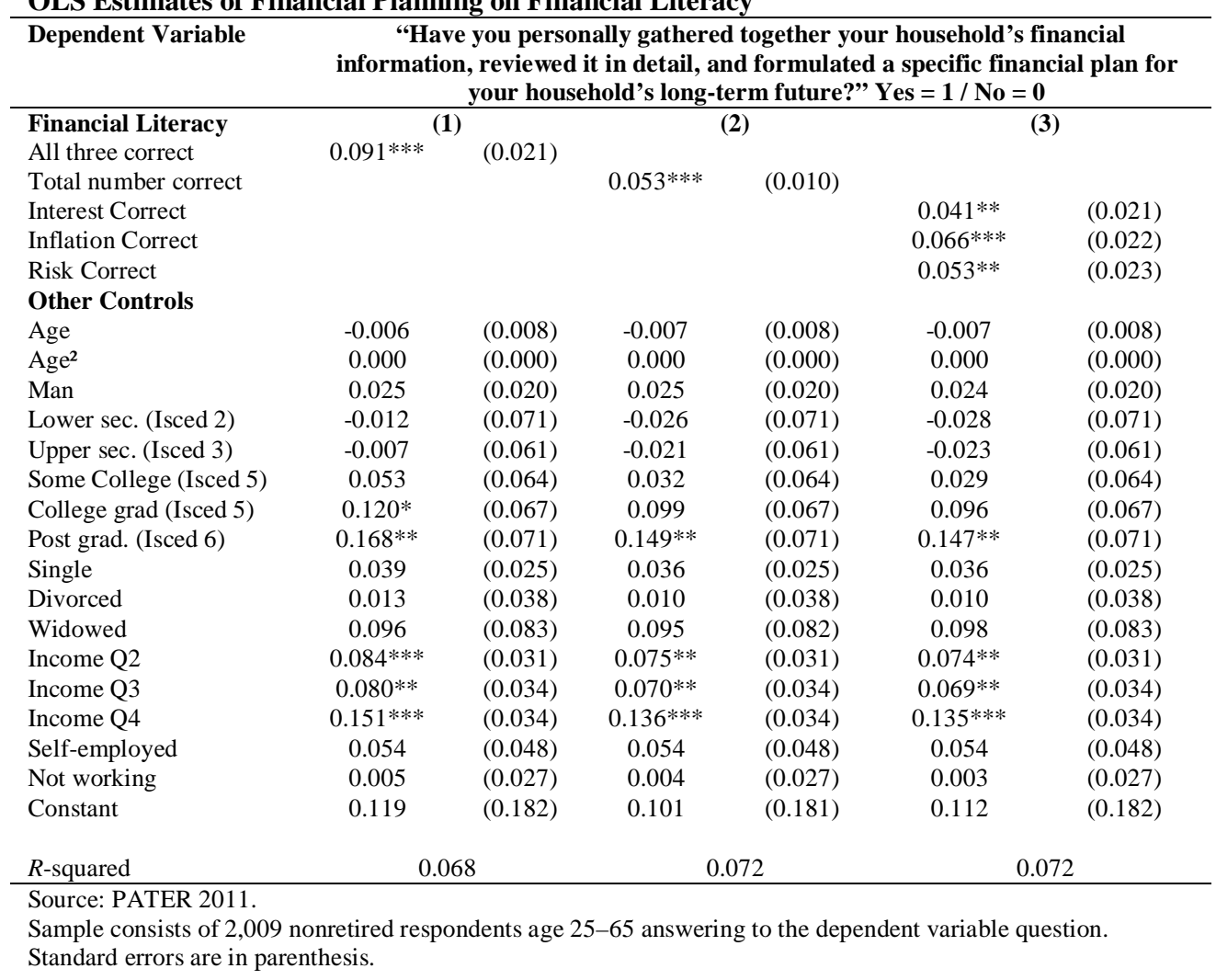

\footnotetext{
${ }^{14}$ We used a variable to assess parents' frequency of reading economic and financial press and another assessing whether respondents' parents planned for retirement or not. We also used a variable assessing the level of mathematics the respondent had when he or she attended school.

${ }^{15}$ For more details, see Arrondel et al. (2013).
} 


\section{Discussion and Conclusion}

Our findings on financial literacy in France are in line with those obtained for other developed countries. Many respondents have difficulty dealing with fundamental financial concepts such as risk diversification, inflation, or interest compounding: less than a third of respondents are able to correctly answer the three questions used to assess financial literacy. We confirm that some subpopulations are more vulnerable than others: women, young adults, and the elderly as well as less-educated people.

We also conduct an original analysis of the heterogeneity of financial knowledge across the political and ideological spectrum in France. We find that centrist voters (characterized in France by a "liberal" view of the economy) perform better than others on financial literacy measures.

These differences in financial knowledge across the population are correlated with differences in the propensity to plan: people with higher financial literacy are more likely to be engaged in the preparation of a clearly defined financial plan for the long-term future. Encouraging policies that promote financial literacy might then be effective in encouraging people to think ahead and plan for their financial future. However, promoting financial literacy may not be sufficient to affect the propensity to plan among impatient consumers.

Indeed, if we refer to the life cycle theory, an individual's time horizon depends both on life expectancy and time preferences. Some people are impatient and prefer current consumption to future consumption. This leaves open further research opportunities to investigate the interactions between preferences, financial literacy, and planning.

\section{Acknowledgments}

We would like to thank Annamaria Lusardi, Muriel Roger, and three anonymous referees for very valuable feedback. This paper presents the views of the authors and should not be interpreted as reflecting the views of the Banque de France.

\section{References}

Alessie R., M. van Rooij and A. Lusardi. 2011. Financial literacy and retirement preparation in the Netherlands. Journal of Pension Economics and Finance 10(4): 527-545. http://dx.doi.org/10.1017/S1474747211000461

Arrondel, L., M. Debbich, and F. Savignac. 2013. Financial literacy and stockholding: New results from a French survey. Draft.

Arrondel, L., and A. Masson. 2013. Measuring savers' preferences: How and why? PSE WP, Paris. (http://www.pse.ens.fr/production-scientifique/documents-de-travail/) 
Agarwal, S., J. C. Driscoll, X. Gabaix, and D. I. Laibson. 2009. The age of reason: Financial decisions over the life-cycle with implications for regulation. Brookings Papers on Economic Activity 40: 51-117. http://dx.doi.org/10.1353/eca.0.0067

Almenberg, J., and J. Save-Soderbergh. 2011. Financial literacy and retirement planning in Sweden. Journal of Pension Economics and Finance 10(4): 585-598. http://dx.doi.org/10.1017/S1474747211000497

Ameriks, J., A. Caplin, and J. Leahy. 2003. Wealth accumulation and the propensity to plan. Quarterly Journal of Economics 118(3): 1007-1048. http://dx.doi.org/10.1162/00335530360698487

Barber, B. M., and T. Odean. 2001. Boys will be boys: Gender, overconfidence, and common stock investment. Quarterly Journal of Economics 116(1): 261-292. http://dx.doi.org/10.1162/003355301556400

Ben Salem, M., D. Blanchet, A. Bozio, and M. Roger. 2010. Labor force participation by the elderly and employment of the young: The case of France. In Social security programs and retirement around the world: The relationship to youth employment, ed. J. Gruber and D. A. Wise, 119-146. Chicago, IL: University of Chicago Press. http://dx.doi.org/10.7208/chicago/9780226309507.003.0005

Bucher-Koenen, T., and A. Lusardi. 2011. Financial literacy and retirement planning in Germany. Journal of Pension Economics and Finance 10(4): 565-584. http://dx.doi.org/10.1017/S1474747211000485

COR. 2013. Retraites: Un état des lieux du système français. 12ème rapport. Paris. (http://www.cor-retraites.fr/IMG/pdf/doc-1893.pdf)

Credoc. 2011. La culture financière des français. Paris.(http://www.credoc.fr/ $\mathrm{pdf} / \mathrm{Sou} / \mathrm{La}$ culture financiere des Francais 2011.pdf)

Elgie, R. 2003. Political institutions in contemporary France. Oxford, UK: Oxford University Press.

Fornero, E., and C. Monticone. 2011. Financial literacy and pension plan participation in Italy. Journal of Pension Economics and Finance 10(4): 527-545. http://dx.doi.org/10.1017/S1474747211000473

Haas, P. 2012. Les Français et l'économie. Bulletin de la Banque de France, № 190.

Jappelli, T., and M. Padula. 2013. Investment in financial literacy, social security and portfolio choice. Draft Observatoire Européen de l'Epargne. (http://virgo.unive.it/seminari_economia/Padula.pdf)

Kaustia, M., and S. Torstila. 2011. Stock market aversion? Political preferences and stock market participation. Journal of Financial Economics 100(1): 98-112. http://dx.doi.org/10.1016/j.jfineco.2010.10.017

Klapper, L., and G. A. Panos. 2011. Financial literacy and retirement planning: The Russian case. Journal of Pension Economics and Finance 10(4): 599-618. http://dx.doi.org/10.1017/S1474747211000503

King, M. A., and J. I. Leape. 1987. Asset accumulation, information, and the life cycle. NBER Working Paper No. 2392. National Bureau of Economic Research, Cambridge, MA.

Lusardi, A., and O. S. Mitchell. 2011a. Financial literacy around the world: An overview. Journal of Pension Economics and Finance 10(4): 497-508. http://dx.doi.org/10.1017/S1474747211000448 
. 2011b. Financial literacy and retirement planning in the United States. Journal of pension economics and finance 10(4): 509-525. http://dx.doi.org/10.1017/S147474721100045X

. 2011c. Financial literacy and planning: Implications for retirement wellbeing. In Financial Literacy: Implications for Retirement Security and the Financial Marketplace. Eds. O. S. Mitchell and A. Lusardi. Oxford, Oxford University Press: 17-39. http://dx.doi.org/10.1093/acprof:oso/9780199696819.003.0002

Lusardi, A., O. S. Mitchell, and V. Curto. 2010. Financial literacy among the young. Journal of Consumer Affairs 44(2): 358-380. http://dx.doi.org/10.1111/j.1745-6606.2010.01173.x

. 2012. Financial sophistication in the older population. NBER Working Paper No. 17863. National Bureau of Economic Research, Cambridge, MA.

Lusardi, A., and P. Tufano. 2009a. Debt literacy, financial experiences, and overindebtedness. NBER Working Paper No.14808. National Bureau of Economic Research, Cambridge, MA.

- 2009b. Teach workers about the peril of debt. Harvard Business Review 87(11): 22-24.

Nadeau, R., M. Foucault, and M. Lewis-Beck. 2010. Patrimonial economic voting in French legislative elections. West European Politics 33(6): 1261-1277. http://dx.doi.org/10.1080/01402382.2010.508907

Observatoire des retraites. 2009. La retraite en France: Statistiques, définitions, tendances, projections. Les chiffres de la retraite. No. 5. (http://www.observatoireretraites.org/uploads/tx orpublications/LORC5.pdf)

Rémond, R. 1969. The right wing in France: From 1815 to de Gaulle. Philadelphia, PA: University of Pennsylvania Press.

van Rooij, M., A. Lusardi, and R. Alessie. 2011. Financial literacy and stock market participation. Journal of Financial Economics 101(2): 449-472.

$\frac{\text { http://dx.doi.org/10.1016/j.jfineco.2011.03.006 }}{\text {. 2012. Financial literacy, retirement planning and household wealth. Economic }}$ Journal 122(560): 449-478. http://dx.doi.org/10.1111/j.1468-0297.2012.02501.x 


\section{Appendix}

\section{Table A1}

Summary Statistics on Monopoly Question (weighted \%)

\begin{tabular}{lcc}
\hline Monopoly & Full Sample & Age 25-65 \\
2 times & 4.33 & 4.76 \\
3 times & 2.43 & 2.97 \\
4 times & 18.97 & 21.73 \\
5 times & 36.45 & 38.79 \\
More than 5 times & 14.77 & 14.59 \\
DK & 23.05 & 17.16 \\
RF & 0.00 & 0.00 \\
\# Observations & $\mathbf{3 , 6 1 6}$ & $\mathbf{2 , 4 5 9}$ \\
\hline
\end{tabular}

Source: PATER 2011.

The question is as follows: You play Monopoly. You have earned $€ 1,000$ and the bank offers to pay $20 \%$ every time you go through the corner square GO. You need $€ 2000$ to buy a hotel. How often do you need to pass through the first corner square to buy the hotel? 2 times; 3 times; 4 times; 5 times; More than 5 times; Do not know

Table A2

Political Opinion by Socio-demographic variables (weighted \%)

\begin{tabular}{lcccccc} 
& Left & Center & Right & Anarchist & $\begin{array}{c}\text { No pol. } \\
\text { opinion }\end{array}$ & $\begin{array}{c}\text { Full } \\
\text { sample }\end{array}$ \\
Age & & & & & & \\
Under 35 & 25.54 & 24.75 & 24.83 & 30.37 & 34.03 & 27.96 \\
36-50 & 23.51 & 25.57 & 24.63 & 24.53 & 27.48 & 25.48 \\
51-65 & 30.15 & 25.29 & 23.69 & 31.10 & 22.81 & 25.33 \\
Over 65 & 20.80 & 24.39 & 26.86 & 13.99 & 15.68 & 21.23 \\
Sex & & & & & & \\
Male & 50.90 & 51.52 & 51.04 & 58.74 & 39.39 & 47.41 \\
Female & 49.10 & 48.48 & 48.96 & 41.26 & 60.61 & 52.59 \\
Education & & & & & & \\
Primary (Isced 1) & 8.79 & 4.69 & 9.12 & 5.20 & 10.47 & 8.51 \\
Lower sec. (Isced 2) & 6.64 & 4.80 & 7.89 & 10.17 & 8.18 & 7.04 \\
Upper sec. (Isced 3) & 51.01 & 44.82 & 48.87 & 53.81 & 58.91 & 51.77 \\
Some College (Isced 5) & 14.90 & 20.13 & 18.44 & 30.83 & 14.13 & 16.63 \\
College grad (Isced 5) & 12.39 & 15.52 & 9.09 & 0.00 & 5.77 & 10.14 \\
Post grad. (Isced 6) & 6.28 & 10.04 & 6.59 & 0.00 & 2.54 & 5.92 \\
Employment Status & & & & & & 3.30 \\
Self employed & 2.00 & 2.02 & 4.50 & 6.86 & 3.30 & 3.00 \\
Not employed & 14.32 & 10.33 & 14.09 & 17.91 & 23.88 & 16.50 \\
Working & 52.87 & 57.13 & 47.21 & 55.28 & 51.35 & 52.05 \\
Retired & 30.81 & 30.52 & 34.20 & 19.95 & 21.47 & 28.45 \\
\# Observations & 851 & 752 & 778 & 17 & 1,092 & 3,490 \\
\hline Source: PATER 2015
\end{tabular}

Source: PATER 2011.

The number of observations does not sum up to 3,616 because of no answers. 
Table A3

OLS Estimates of Financial Literacy on Political Opinion and Sociodemographics

\begin{tabular}{|c|c|c|c|c|}
\hline \multirow{2}{*}{$\begin{array}{l}\text { Dependent Variable } \\
\text { Political Opinion }\end{array}$} & \multicolumn{2}{|c|}{ All 3 Correct } & \multicolumn{2}{|c|}{$N$ Correct } \\
\hline & & & & \\
\hline Centre & $0.059 * * *$ & $(0.022)$ & $0.210 * * *$ & $(0.048)$ \\
\hline Left-wing & -0.001 & $(0.022)$ & 0.014 & $(0.047)$ \\
\hline Anarchist & 0.070 & $(0.106)$ & 0.130 & $(0.232)$ \\
\hline No Political Opinion & $-0.087 * * *$ & $(0.020)$ & $-0.258 * * *$ & $(0.044)$ \\
\hline \multicolumn{5}{|l|}{ Socio-demographic } \\
\hline \multicolumn{5}{|l|}{ Controls } \\
\hline Age & $0.011^{* * *}$ & $(0.003)$ & $0.024 * * *$ & $(0.006)$ \\
\hline Age $^{2}$ & $-0.000 * * *$ & $(0.000)$ & $-0.000 * * *$ & $(0.000)$ \\
\hline Man & $0.072^{* * *}$ & $(0.015)$ & $0.166^{* * *}$ & $(0.033)$ \\
\hline Lower sec. (Isced 2) & 0.059 & $(0.036)$ & $0.249 * * *$ & $(0.079)$ \\
\hline Upper sec. (Isced 3) & $0.085^{* * *}$ & $(0.027)$ & $0.328 * * *$ & $(0.060)$ \\
\hline Some College (Isced 5) & $0.214 * * *$ & $(0.033)$ & $0.628 * * *$ & $(0.072)$ \\
\hline College grad (Isced 5) & $0.241^{* * *}$ & $(0.037)$ & $0.702^{* * *}$ & $(0.080)$ \\
\hline Post grad. (Isced 6) & $0.368 * * *$ & $(0.042)$ & $0.828 * * *$ & $(0.092)$ \\
\hline Single & $0.043^{* *}$ & $(0.021)$ & $0.120 * * *$ & $(0.045)$ \\
\hline Divorced & 0.040 & $(0.028)$ & 0.061 & $(0.060)$ \\
\hline Widowed & 0.030 & $(0.031)$ & -0.047 & $(0.068)$ \\
\hline Income Q2 & $0.054 * *$ & $(0.022)$ & $0.264 * * *$ & (0.047) \\
\hline Income Q3 & $0.119 * * *$ & $(0.025)$ & $0.349 * * *$ & $(0.054)$ \\
\hline Income Q4 & $0.209 * * *$ & $(0.025)$ & $0.606 * * *$ & $(0.054)$ \\
\hline Self-employed & 0.064 & $(0.048)$ & 0.082 & (0.104) \\
\hline Not working & 0.007 & $(0.020)$ & 0.061 & (0.043) \\
\hline Constant & $-0.233^{* * *}$ & $(0.075)$ & $0.386^{* *}$ & $(0.162)$ \\
\hline$R$-squared & \multicolumn{2}{|c|}{0.134} & \multicolumn{2}{|c|}{0.188} \\
\hline
\end{tabular}

Source: PATER 2011.

Sample consists of 3,490 households who answered the question on political opinion.

Standard errors are in parentheses. 